\section{The Use of Gold Mercaptides for Decorative Precious Metal Applications}

\author{
Peter T Bishop \\ Johnson Matthey Technology Centre, \\ Blounts Court Road, Sonning Common, Reading, \\ RG4 9NH, UK \\ E Mail : bishopt@matthey.com
}

\section{Received: 27 June 2002}

An overview of the use of soluble gold mercaptide compounds as precursors in Decorative Precious Metal (DPM) ink formulations, for application onto ceramic, glass and plastic substrates, is given. Synthetic, thermal, structural and metallisation properties are highlighted, together with the advantages that these precursors show for DPM ink applications. The literature reviewed covers the period 1960 to 2001. Mechanistic studies are described and likely future trends indicated.

\section{Introduction}

This article gives an overview of the use of molecular goldmercaptide species as precursors in decorative bright films. Attention is drawn to the synthetic routes employed, thermal and structural data of the gold compounds and documented advantages these precursors have displayed within the decorative gold ceramic and glass markets. Not highlighted are gold precursors associated with metal organic chemical vapour deposition (MOCVD) commonly used in the electronics industry, details of which are given elsewhere (1). Excellent reviews on the application technologies $(2,3)$ and the range of gold precursors (2) investigated have appeared in previous publications. Attention is drawn to where further work could be useful to answer some of the questions derived from the patent and published papers.

The literature cited in this review uses a variety nomenclature for describing gold precursors. For clarity, reference throughout the text is made to gold-mercaptides rather than gold-thiolates, the alternative terminology, and the same nomenclature is adopted for describing the mercaptide ligands as discussed in the individual literature.

Liquid precious metal inks for decoration of ceramic ware, such as bone china and porcelain, have been known for approximately four hundred years (2). The first gold inks were simply gold powder dispersed into naturally occurring resinous materials and gave, on firing at $400-800^{\circ} \mathrm{C}$, off bright films that could be lightly burnished, (rubbed with a mild abrasive), to produce lustrous decorative gold effects. It was not until the 1890s that bright gold films were produced from soluble gold materials prepared by reaction of gold halides with sulphurised terpenes or balsams. The chemical nature of the soluble bright gold portion has not been fully revealed over the intervening years. Alternative strategies to produce bright films have been investigated. The most commonly adopted approach has been to use characterised polymeric gold-mercaptide compounds which display a wide range of solubility in hydrocarbons and water as discussed below. Commercially available gold ink compositions are known to contain soluble gold species if bright reflective gold films are required. Decorative effects on ceramic and glassware are shown in Figures 1 and 2 where goldmercaptides can be used as key precursors to achieve these effects.

Gold-mercaptide precursors can be used in conjunction with silver mercaptides and other minor metal additions to improve colour and adhesion on ceramic or glassware. Typical application is by screen-printing the gold ink onto water-slide transfer paper, or by direct printing via silicone pad or screen-printing directly onto flat ware. The resin or polymer and solvent system employed dictates the rheology and drying rates of the ink. Firing temperatures range from 


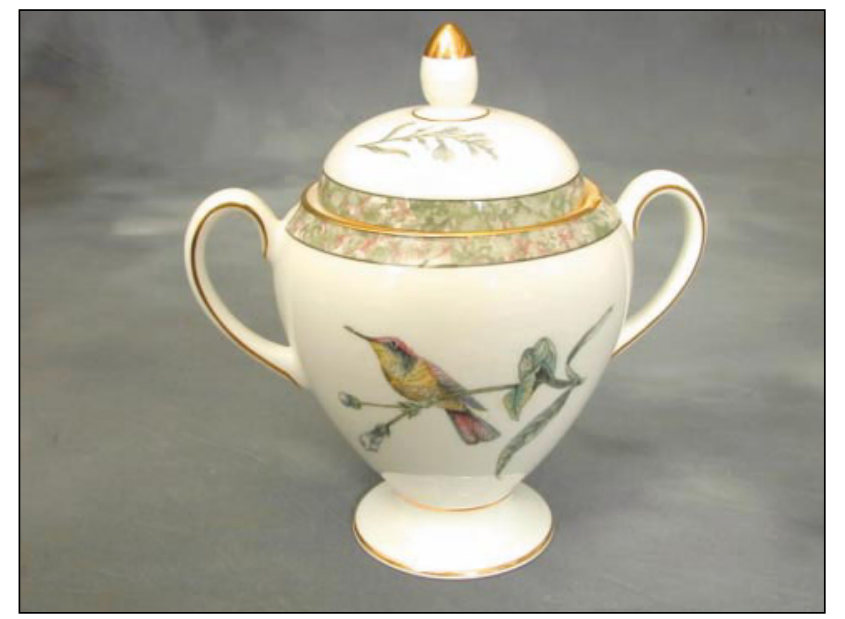

\section{Figure 1}

Gold bands produced by application of an ink containing soluble gold precursors, followed by firing in the region of $700-900^{\circ} \mathrm{C}$

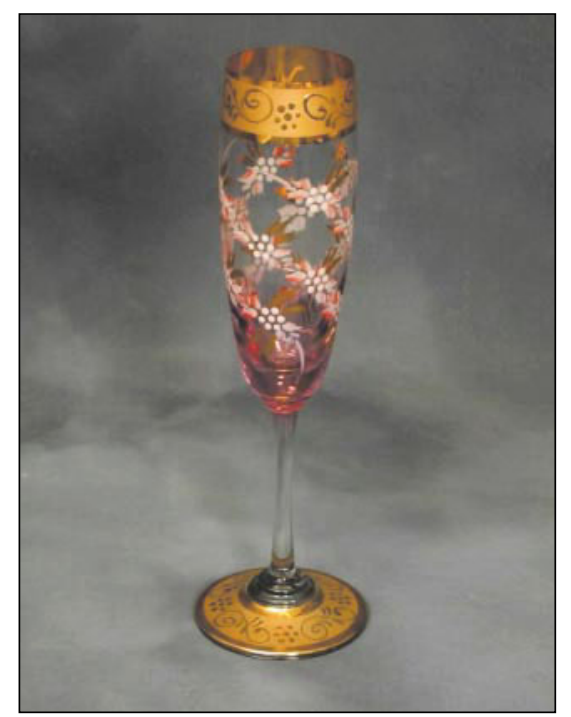

Figure 2

Gold decoration onto glassware, where a combination of bright gold and off-bright gold is seen over and around an etched glass surface

500 to $950^{\circ} \mathrm{C}$ depending on the substrate. The firing is expected to remove organic residues and to leave adherent gold films with high lustres that can be burnished, or reflective golden films. General reviews on liquid gold inks and Decorative Precious Metal (DPM) technology have appeared in previous issues of Gold Bulletin (3-5).

Initial studies, around the turn of the last century, involved the preparation of sulphur-based ligands derived from the synthesis of cyclic terpene derivatives with mercaptide groups. These materials, referred to as sulphoresinates, were not well defined and may well have been mixtures of mercaptides and sulphides (6). Further to this work, gold compounds of terpene mercaptides, for example $\alpha$ or $\beta$ pinene or dipentene, were used as precursors to produce bright decorative gold inks (7). The advantages of these materials are that they are more stable and soluble than the sulphoresinates described above and can be prepared with a high degree of consistency.

Due to advantages seen for the terpene mercaptides Fitch and co-workers from the Engelhard Corporation investigated a diverse range of gold-mercaptides for decorative applications dating from the early 1960s. Work has progressed thoughout the last 40 years to reveal the potential of gold mercaptides for decorative applications arising from an almost limitless ability to vary the $R$ group in the AuSR compounds. The solubility can vary from water through to glycols/alcohol to aliphatic/aromatic hydrocarbons. In addition, gold-mercaptides show high degrees of stability within complex ink formulations containing resins and common metal additions found in decorative precious metal compositions such as Rh, Ag or Bi. The above points support the dominance of the patent literature on the use of gold mercaptides for decorative applications and will be illustrated in this review. The lack of published mechanistic studies into the metallisation processes also becomes apparent. Recommendations for investigating these thermal decomposition reactions will be indicated.

This present review describes work published after these early studies; it begins in the early 1960s and continues up to the present time.

\section{Gold-Mercaptides Synthesis}

The use of gold(I)-thiolate species (or mercaptides as commonly referred to in the literature and used hereafter) as precursors in decorative gold inks was first reported in a systematic manner in the early to mid 1960s by Fitch and coworkers. A series of homoleptic Au(I)-mercaptide species were claimed with ligands ranging from primary mercaptides (8) through to secondary (9) and tertiary (10) mercaptides, then to aryl or aromatic (11) containing species. Their generalised structures with respect to the mercaptide ligand are shown in Figure 3 (a-d).

The primary gold-mercaptides employed (8) were within the range of 1-20 C atoms and preferred materials contained 1-8 C. These gold precursors were prepared using gold chloride solutions and 4-5 mole equivalents of the mercaptide ligand. A specific example reported is the synthesis of $\{\text { AuSR }\}_{n}$ where $\mathrm{R}=\mathrm{C}_{2} \mathrm{H}_{5}$. The reaction proceeds as depicted in the general equation (1) below:

$$
\mathrm{AuCl}_{4}^{-}+3 \mathrm{HSR} \longrightarrow\{\mathrm{AuSR}\}_{n}+\mathrm{RS}-\mathrm{SR}+3 \mathrm{HCl}+\mathrm{Cl}^{-}
$$

The mercaptide ligand is used as a sacrificial reductant. Au(III) is reduced to $\mathrm{Au}(\mathrm{I})$ with simultaneous formation of disulphide. As seen from the equation, two mole equivalents of thiol are used for the reduction, which, from a commercial viewpoint, 


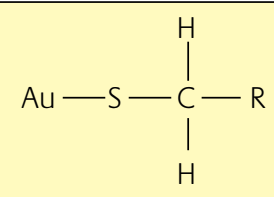

(a)

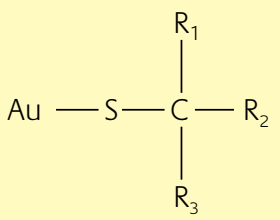

(c)

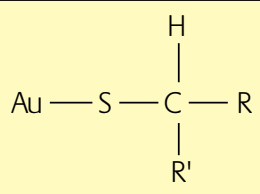

(b)

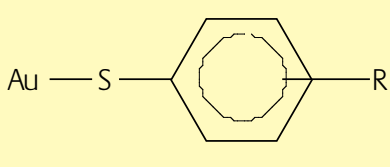

(d)

\section{Figure 3}

Gold mercaptide structures. (a) where $R=a l k y l$, alkylaryl or aryl, $R=1-20 \mathrm{C}$ atoms (b) where $R$ and $R^{\prime}=$ alkyl, cycloalkyl, aryl, aralkyl for alkyl=methyl ethyl, butyl up to octadecyl, for cycloalkyl=cylcobutyl, cyclopentyl, cyclohexyl; for aryl=phenyl, naphthyl, phenanthryl; aralkyl= benzyl, 2phenylethyl, phenylbutyl, (c) where $R_{1}, R_{2}$ and $R_{3}$ are alkyl groups from 1-40 carbons, examples cited are tert-amyl, tert-octyl, tert-dodecyl, tert-tetradecyl, tert-butyl, tert-nonyl, tert-dodecyl and

(d) where $R=4-12$ C atoms and mono/di substituted into the aromatic ring, preferred groups are, $p$-tert-butylphenyl, o-methyl-p-tert-

butylphenyl, p-nonylphenyl, p-dodecylphenyl, p-octadecylphenyl, 2,4di-isopropylphenyl, 2,4-di-tert-butylphenyl

Gold-mercaptides depicted in (a-d) have been characterised by $\%$ Au determined from the resulting white to yellow powders together with melting point data. The gold content is in agreement with the stoichiometry of AuSR

can be expensive. The patent does, however, mention the use of $\mathrm{Au}(\mathrm{I})$ halides as precursors that eliminate the reduction step and, therefore, reduce the amount of thiol required. This is discussed in more detail below.

The use of these gold-mercaptides is restricted to metallising precursors for burnish or polish gold compositions, where turpentines or balsams are used as the main application vehicle for brushing application. The resulting gold films were described as slightly matte; brighter films were produced by polishing. Of interest is the fact that these materials are cited as the only gold source used, whereas alternative commercial burnish formulations usually contain fine gold powders, typically within the 1-5 micron range.

Fitch et al go on to describe the use of gold compounds containing secondary mercaptide ligands for use in bright decorative films (9). The range of ligands used is wide, see Figure 3b, where $\mathrm{R}$ and $\mathrm{R}^{\prime}$ can be alkyl, cycloalkyl, aryl or aralkyl moieties. The main advantage of these materials is their low metallisation temperatures, which makes them useful for application onto plastics and other non-refractory materials such as leather or textiles.

Details of alternative synthetic routes to gold(I)mercaptides are discussed. Of particular note is the use of alkyl sulphides that act as two electron reducing agents for conversion of $\mathrm{Au}(\mathrm{III})$ to $\mathrm{Au}(\mathrm{I})$ as represented by the general equation (2):

$$
\mathrm{AuX}_{4}^{-}+2 \mathrm{R}-\mathrm{S}-\mathrm{R}+\mathrm{H}_{2} \mathrm{O} \longrightarrow \mathrm{R}_{2} \mathrm{~S}-\mathrm{Au}-\mathrm{X}+\mathrm{R}_{2} \mathrm{~S}=\mathrm{O}+2 \mathrm{H}^{+}+3 \mathrm{X}^{-}
$$

where $\mathrm{X}=\mathrm{Cl}, \mathrm{Br}$, I and $\mathrm{R}=$ methyl, ethyl, butyl, octyl.

The above is the first report giving details of these reactions. A wider range of sulphide-reducing agents has subsequently been used. Reaction of a stoichiometric quantity (one mole equivalent) of the desired mercaptide allowed for economical use of the mercaptide ligand and removal of the disulphide by-products, seen above, from the overall reaction(3):

$$
\mathrm{R}_{2} \mathrm{~S}-\mathrm{A}_{U}-\mathrm{X}+\mathrm{HSR^{ \prime }} \longrightarrow\left\{\mathrm{AuSR}^{\prime}\right\}_{\mathrm{n}}+\mathrm{HX}+\mathrm{R}_{2} \mathrm{~S}
$$

Use of tert-alkyl mercaptides has been described by Fitch (10), Figure 3c. This patent preceded the one discussed above and also details the use of di-alkyl sulphides as effective two electron reducing agents for $\mathrm{Au}(\mathrm{III})$ to $\mathrm{Au}(\mathrm{I})$. The most soluble gold mercaptides from this series appear to contain over twelve carbon atoms in the mercaptide ligand and are most suited for use in bright gold ink formulations. A specific example is Au(I)-tert-dodecyl mercaptide, which exhibits high hydrocarbon solubility and high gold content. Ligands containing less than twelve carbon atoms are suitable for use in burnish gold compositions where partial or no solubility is required in hydrocarbon solvents.

The main advantage of these materials is the low temperature required for bright conductive film formation, which is a re-occurring theme in the Fitch patent series. For example, Au(I)-tert-dodecyl mercaptide was applied to a glass slide in a mixture of toluene and turpentine and heated to $160^{\circ} \mathrm{C}$ until a bright conductive film is formed. Similar experiments using terpene-based mercaptides, such as Au(I)pinene mercaptide, did not produce such films at these temperatures.

The last phase of the work reported by Fitch and coworkers (11) was to investigate the potential of arylcontaining gold-mercaptides of general formula Au-SAr, where $\mathrm{Ar}$ = benzene, which can be mono- or di-substituted with alkyl groups containing 4-12 carbon atoms; the alkyl groups can be linear or branched. A specific example cited, possessing high organic solubility, is p-tert-butylphenyl mercaptide, which in chloroform exceeded $30 \%$ by weight of compound. In contrast, the unsubstituted gold-phenyl mercaptide was essentially insoluble in chloroform. Another example cited is o-methyl-p-tert-butylphenyl mercaptide, which has a solubility of $40 \%$ by weight of the compound whereas o-methylphenyl mercaptide is virtually insoluble. Based on these examples, it appears that the parasubstituted group, in this case tert-butyl, dominates the solubility characteristics of the gold compound. 


\section{Thermal Properties}

Table 1 lists gold metallisation temperatures for a range of aliphatic, benzylic and aromatic gold-mercaptide compounds described in the Fitch patents.

The aliphatic and benzylic-mercaptides, compounds numbered $10-17$ in Table 1 exhibit a relatively narrow temperature range for metallisation or thermal decomposition ie. $150^{\circ} \mathrm{C}$ to $205^{\circ} \mathrm{C}$. There does not seem to be an obvious trend in the temperatures with respect to ligand structure or physical properties such as melting or boiling points of the mercaptides. Parameters that may account for the apparent random spread of metallisation temperatures could be variations in polymeric structure of these homoleptic gold(I)-mercaptides. This is believed to be influenced by steric bulk near to the sulphur donor atom. Another influential parameter on metallisation is the tendency for aliphatic mercaptides to undergo metal assisted C-S bond cleavage (12). Such reactions result in metalsulphide products. If such reactions occur during thermolysis of gold(I)-mercaptides, then detailed thermal analysis studies are required to enable the control of preferred mechanisms.

For the aryl mercaptides, a segregation in metallisation temperatures is seen for the series of $o / \mathrm{m} / \mathrm{p}$-methylphenylmercaptide compounds (compounds 2-4, Table 1). The omethyl derivative has a metallisation temperature of $215^{\circ} \mathrm{C}$, whereas the $m$ - and $p$-products metallise at 130 and $135^{\circ} \mathrm{C}$ respectively. The cause of these temperature differences is unclear; however, if this data is taken in isolation, it could be that steric bulk associated with the o-methyl group influences structural parameters of the gold polymer and hence, the physical properties such as metallisation temperature. Such an explanation contrasts with a metallisation temperature of $230^{\circ} \mathrm{C}$ for the $p$-tert-butylphenyl material (Compound 7) and $105^{\circ} \mathrm{C}$ for the di-substituted o-methyl-p-tert-butylphenyl derivative (Compound 8) where, in the latter case, a temperature similar to that of compound 2 would be expected. No direct correlation can be made as to thermal metallisation temperature and chemical composition of the gold precursor and further studies are required to understand why subtle variations within the $\mathrm{R}$ group on the mercaptide-ligand can give rise to wide variations in metallisation temperature.

\section{Stuctural Properties}

Little is known about the structural aspects of homoleptic gold mercaptide compounds used in DPM formulations, with only a few examples reported in the open literature (13-15). These examples involve the use of sterically-hindered mercaptides as ligands yielding low nuclearity ring structures with the $A u(I)$ in a 2-coordinate linear geometry linked by bridging mercaptide ligands.

Simple non-sterically-hindered Au(I)-mercaptides are polymeric in nature and tend to be amorphous and this
Table 1 Mercaptide Compounds

\begin{tabular}{|c|c|c|}
\hline \multicolumn{2}{|r|}{ Compound } & $\begin{array}{c}\text { Metallisation } \\
\text { Temperature, }{ }^{\circ} \mathrm{C}\end{array}$ \\
\hline 1 & Sulphoresinate & 270 \\
\hline 2 & o-methylphenyl & 215 \\
\hline 3 & m-methylphenyl & 130 \\
\hline 4 & p-methylphenyl & 135 \\
\hline 5 & mixed-methylphenyl & 100 \\
\hline 6 & phenyl & 115 \\
\hline 7 & p-tert-butylphenyl & 230 \\
\hline 8 & o-methyl-p-tert-butylphenyl & 105 \\
\hline 9 & pinene & 205 \\
\hline 10 & isopropyl & 165 \\
\hline 11 & sec-butyl & 150 \\
\hline 12 & 1-methylheptyl & 165 \\
\hline 13 & 1-methyldodecyl & 170 \\
\hline 14 & 1-methyloctadecyl & 180 \\
\hline 15 & $\alpha$-methylbenzyl & 165 \\
\hline 16 & $\alpha$-butylbenzyl & 165 \\
\hline 17 & $\alpha$-undecylbenzyl & 145 \\
\hline 18 & tert-dodecyl ${ }^{*}$ & 160 \\
\hline 19 & tert-amyl * & 190 \\
\hline 20 & tert-octyl * & 170 \\
\hline 21 & tert-butyl * & 195 \\
\hline
\end{tabular}

Note: Compounds are as gold(I)-mercaptide; thermal data refers to the minimum temperature to obtain conductive films obtained by heating $10 \%$ gold compound on a glass slide and measuring conductivity every $5^{\circ} \mathrm{C}$.

* Visually determined thermal decomposition of gold mercaptides by observation of darkening and decomposition in capillary tubes heated at $5^{\circ} \mathrm{C} /$ minute.

precludes crystal growth from solution for single crystal structure analysis. Crystals of the compound nominally given the stoichiometry Au-S( $\left.\mathrm{C}_{6} \mathrm{H}_{4}-\mathrm{p}-\mathrm{CMe}_{3}\right)$, discussed in a Fitch patent (11) and subsequent publications (16), have been grown from ethoxybenzene (17). A model of the solid state structure is depicted in Figure 4 and corresponds to $\left[\mathrm{Au}_{10}(\mathrm{SR})_{10}\right]$. What is intriguing about this structure is the dominance of aurophilic Au-Au interactions that leads to a gold-catenane structure involving two interpenetrating pentagons defined by five bridging mercaptides and five $A u(I)$ ions and a gold at the centre of each pentagon. The pentagon rings reveal $A u(I)$ to have a linear geometry ligated by bridging mercaptide anions. The structure is stabilised by $\mathrm{Au}-\mathrm{Au}$ contacts (average $30.5 \mathrm{pm}$ ) and longer Au-Au interactions (average $35.9 \mathrm{pm}$ ). The dominance of $\mathrm{Au}-\mathrm{Au}$ interactions, which dictates the solid state structure, is seen in other $\mathrm{Au}(\mathrm{l})$ complexes containing phosphine ligands. 


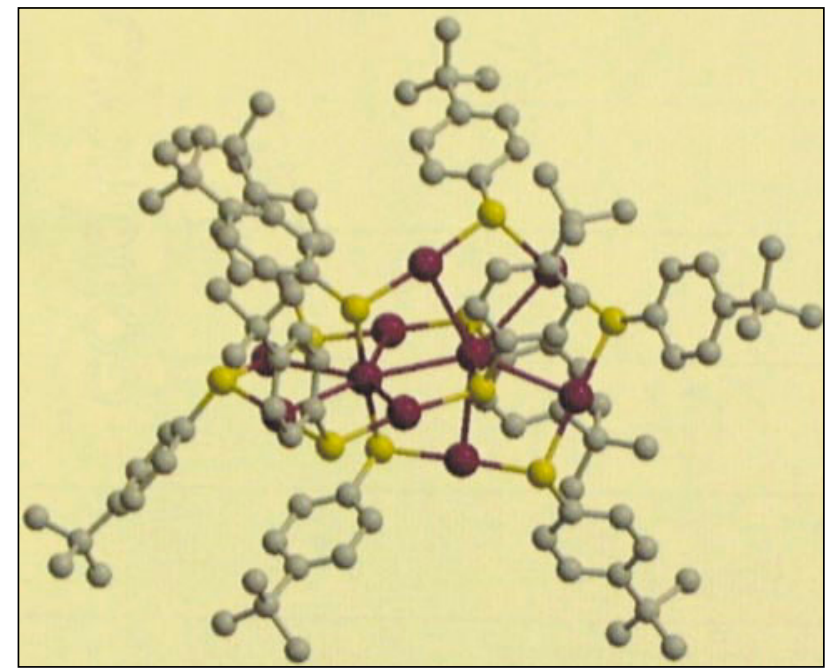

Figure 4

$\left[A u_{10}(S R)_{10}\right]$ where $S R=p$-tert-butylphenyl mercaptide, purple sphere=Au; Yellow spheres=Sulphur; grey spheres=p-tert-butylphenyl moiety Au-S range $=228.8-234.3 \mathrm{pm}$, S-Au-S range $=172.52-178.01^{\circ}, \mathrm{Au} . . . \mathrm{Au}$ interactions average $=305 \mathrm{pm}$

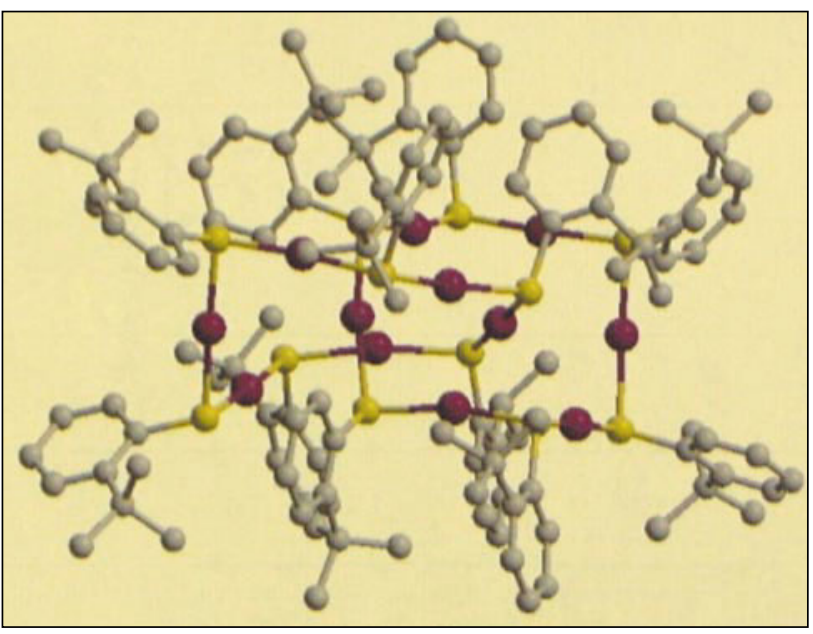

Figure 5

$\left[A u_{12}(S R)_{12}\right]$ where $S R=0$-tert-butylphenyl mercaptide, purple sphere=Au; Yellow spheres=Sulphur; grey spheres=o-tert-butylphenyl moiety Au-S range $=228.7-243.5 \mathrm{pm}, \mathrm{S}-\mathrm{Au}-\mathrm{S}$ range $=162.8-178.2^{\circ}, \mathrm{Au} . . . \mathrm{Au}$ interactions range $=316-330 \mathrm{pm}$.

However this specific structural arrangement has not been previously observed for homoleptic gold thiolates.

On moving the tert-butyl substituent on the aromatic mercaptide to the o-position, the solid state structure depicted in Figure 5 arises (17), now having the stoichiometry of $\left[\mathrm{Au}_{12}(\mathrm{SR})_{12}\right]$ and effectively two extra mercaptide ligands and gold atoms in the array. Again, two interpenetrating rings are observed, this time hexagonal in nature, which each consist of six bridging mercaptides and six $A u(I)$ ions linearly coordinated as for $\left[A u_{10}(S R)_{10}\right]$. Au-Au interactions are longer than those seen in the $\mathrm{Au}_{10}$ structure. The steric bulk in the $o$-position, due to the tert-butyl group, appears to be responsible for the higher nuclearity compound where steric constraints are relieved by the larger ring sizes. The opposite would be expected if Au-Au interactions did not dominate the solid state structures of these unique arrays. Certainly these structural studies have indicated the possibility of a wide range of arrays for oligiomeric/polymeric goldmercaptides with the added dominance of Au-Au interactions influencing structure diversity.

\section{Gold and Silver Compounds}

Fitch et al extended their work on homoleptic goldmercaptide compounds to include silver as new $\mathrm{Au} / \mathrm{Ag}$ mercaptide precursors (18). These are prepared from reaction of the relevant metal-mercaptides at elevated temperatures in a 1:1 stoichiometric ratio shown below:

$$
\mathrm{Au}-\mathrm{SR}+\mathrm{Ag}-\mathrm{SR}_{1} \stackrel{\Delta}{\longrightarrow} \text { AuAgSRSR }_{1}
$$

Also included are oxygen donor ligands for silver, ie Ag-OOCR. A broad range is covered such that compounds of general formula, RS-Au- $Y$ where $Y=R_{1} S-A g$ or Ag-OOCR 2 and $R, R_{1}$ and $R_{2}$ can be combinations of alkyl, esterified carboxyalkyl, alkoxyalkyl, alicyclic, aryl, aralkyl, alkylaryl or terpenyl radicals. A general synthesis involves the reaction of equimolar amounts of the gold and silver together in toluene, followed by heating this mixture to temperatures between $50-120^{\circ} \mathrm{C}$. Temperatures higher than $120^{\circ} \mathrm{C}$ are to be avoided as this leads to decomposition of the precursor materials. Of note is the increase in solubility of the Au/Ag products compared to the single precursors or as room temperature admixtures. Although not conclusive, this evidence indicates that the products are unique and not mixtures and possibly, as yet, uncharacterised Au/Ag clusters. Approximately 145 new compounds containing silver and gold are included in the Fitch patent.

An advantage of the mixed metal compounds is that they metallise at a lower temperature compared to the single gold and silver precursors. Again, metallisation onto non-refractory substances such as plastics or textiles is given as an advantage for these materials. In addition, the colour of the resulting metallic films moves from red shades of gold to the more vibrant yellow/green colours. Golden films from glass slides fired at $150^{\circ} \mathrm{C}$ have been produced from several examples; one highlighted is gold-tert-butyl mercaptide-silver-isooctylthioglycolate. The corresponding gold-tertbutylmercaptide actually metallises at $195^{\circ} \mathrm{C}$, according to earlier Fitch data (Table 1) and clearly demonstrates the difference in metallisation properties of these gold/silver arrays. However, specific examples (Table 1) illustrate where metallisation occurs at much lower temperatures for the single gold precursor.

The work carried out by Fitch et al was the first to demonstrate that well defined homoleptic Au(I)-mercaptide 
compounds could be used for decorative applications. In addition, by careful selection of the organic moiety on the mercaptide ligand, a temperature range to form metallic gold could be identified. Questions that are still unanswered concern the correlation of the thermal properties of the gold precursor with the quality of gold film produced in commercial liquid gold-type compositions. Measurement of film conductivity alone does not answer this question. Commercial compositions, by necessity, contain resinous media and minor metal additives that can mask or influence actual metallisation temperatures. Therefore, more detailed studies are required to probe precursor-gold/film quality relationships. Strategies to answer these questions are discussed later in this review. In addition, more work is required on structural investigation of the gold and gold/silver precursors, where varied and possibly novel structural arrays could be discovered.

\section{Functionalised Gold Mercaptides \\ Esters}

Bicyclic mercaptides such as $\mathrm{Au}(\mathrm{I})$-bornylmercaptide were amongst some of the earliest gold sources used to produce conductive gold films for electronic applications (19). A disadvantage was that these produced undesirable odours during application and particularly so when fired to produce gold films. For this reason, mercaptide ligands terminating in ester groups have been developed which have more acceptable odours (20), eg:<smiles>[X]OC([X])=O</smiles>

where $\mathrm{X}$ represents an alkylene group, $\mathrm{Z}$ an alkyl in which $\mathrm{X}$ is a $C_{1}-C_{3}$ group and $Z$ is a bicyclic alkyl group; eg $Z$ is:

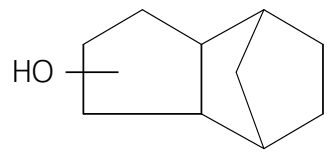

8- or 9-hydroxy-tricyclo-

(5.2.1.02,6) decane

There are a number of isomers of this ligand and the resulting gold compounds. These materials have been used in bright gold formulations for screen-printing applications. A specific advantage is the short drying times required by the formulated ink containing these gold-esters. In some instances, the drying times can be reduced by up to $90 \%$ compared to those used with previously investigated mercaptide-esters.

Mention has been made of the desirability for low odour gold-mercaptides either for the firing processes used to produce gold films, or during handling of these materials. Such inks containing odorous materials would not be commercially viable because the workers who apply and fire these inks on a day-to-day basis would not be able to tolerate the smell!

\section{Water Soluble Gold Precursors}

Some of the more recent developments in gold precursors for decorative films (21) have involved the use of watersolubilising mercaptide ligands for $\mathrm{Au}(\mathrm{I})$. Some of the earliest water soluble gold precursors investigated involved the use of gold(I)-mercaptides using a range of water solubilising functional groups, having the general formula:

Au-S-R-H or Au-S-R-X

where the mercaptide was aliphatic, aromatic or heterocyclic and $\mathrm{X}=$ a nitro group or $-\mathrm{COOH},-\mathrm{SO}_{2} \mathrm{OH},-\mathrm{OH},-\mathrm{C}(\mathrm{O}) \mathrm{NH}_{2},-\mathrm{NH}_{2}$ or $-\mathrm{O}-\mathrm{P}(\mathrm{O})(\mathrm{OH})_{2}$, any of whose $\mathrm{H}$ groups can be substituted. $\mathrm{R}$ represents a divalent organic group. Au(I)-N-(2mercaptopropionyl)glycine, shown below, is the most promising and gives bright films from a wide range of water soluble resins and has a high degree of solution stability:<smiles>CC(S[Ga])C(=O)NCC(=O)O</smiles>

The water solubility in this case is not achieved from the parent compound but by the generation of an ammonium or quaternary ammonium salt, for example triethyl-ammonium, via the carboxylate group within the mercaptide ligand, (Equation 5):

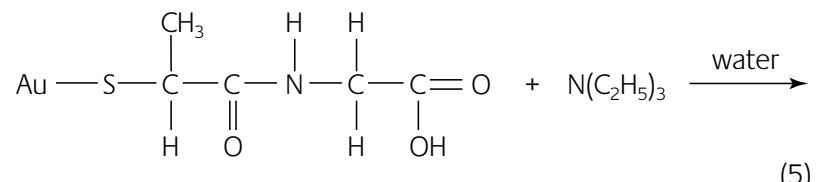

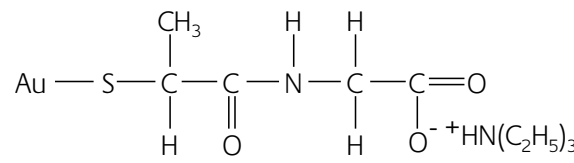

The patent under discussion mentions specific requirements for the ink to produce bright films. Essentially, for mixtures of gold/water/resin and organic solvents, a stepwise thermal decomposition is required, where water is removed followed by co-solvent during progressive heating and at all times a homogeneous film remains. With continued ramping of heat, the resin decomposes in phase with gold metallisation. If this requirement is not met, then heterogeneous films can result which can be dull or off-bright.

Use of $\mathrm{Au}(\mathrm{I}) \mathrm{-N}$-(2-mercaptopropionylglycine) and its salts and the related $\mathrm{Au}(\mathrm{I})-\mathrm{N}$-acetylcysteine compounds in aqueous formulations has been demonstrated (22). Up to $2 \%$ of a solvent can be used in conjunction with surface active agents to modify application properties. It is necessary to decompose gold materials above $200^{\circ} \mathrm{C}$. 
The use of water soluble $\mathrm{Au}(\mathrm{I})$-dimercaptides has also been reported eg (23):<smiles>[Z][V]([Y])(S)[AsH3]</smiles>

where $\mathrm{Q}=$ a tetravalent organic radical containing 2 to 10 carbon atoms, $\mathrm{Y}=\mathrm{a}$ hydrophilic group from the series $-\mathrm{COOH}$, -COO-(cation) or esters of the carboxylate containing ethylene oxide backbones. Gold precursors given in the examples are $\mathrm{Au}(\mathrm{l})$-dimercaptosuccinic acid and also $\mathrm{Au}(\mathrm{I})-2,3-$ or 2,4dimercaptoglutaric acid or 2,3- or $3,4-$ or 2,5 dimercaptoadipic acids or salts. Of note is the observation that the corresponding mono-mercaptides, such as mercaptosuccinic acid, give dull films whereas the dimercaptides yield bright films. The main reason for this is that the extra mercaptide stabilises the gold compound. An added advantage of these new gold compounds is that they can be used in water-only containing inks or with very little cosolvent present, as discussed above.

The theme on using dimercaptides is extended to produce high gold content (60-90\%) precursor materials (24). The dimercaptide-gold species are treated with mineral acids to a $\mathrm{pH}$ of 2 or below. The resulting black to brown powders are filtered from the reaction and the same treatment applied again if required. Successive reactions with acid increase the gold content and widen the S:Au ratio. Of particular note is the nature of these species; for instance, photoelectron spectroscopic studies have shown the gold to have an oxidation state between $\mathrm{Au}(\mathrm{I})$ and $\mathrm{Au}(0)$, indicating the possibility of gold cluster formation. These materials are suitable for use in water based ink systems or in organic inks, depending on the dimercaptide employed.

The synthetic route described for all of the above water soluble gold precursors involves initial reduction of the $\mathrm{AuCl}_{4}{ }^{-}$ anion with di-alkyl sulphides and is similar to the original work reported by Fitch. However, less odorous and more water soluble sulphides have been used, such as di-ethanol sulphide, ethyl-ethanol sulphide or methionine

\section{Non-Sulphur Gold Precursors}

Brief mention is now made of the use of non-sulphur precursors for decorative applications, but there are only a few patents and papers on this topic

The use of non-sulphur containing gold precursors was the subject of a patent application in the early 1980s (25). The main reason for removal of sulphur was to eliminate odorous vapours such as hydrogen sulphide and sulphur-oxides during the firing process. In addition, by not using di-alkyl sulphide reducing agents, a non-sulphur manufacturing route could be achieved. The gold compounds reported have gold assays in the region $15-18 \%$ and are normally isolated as oils. Specific examples involve a pre-reaction with an alkyl amine such as propylene di-amine with a gold chloride solution. The uncharacterised precursor is isolated as a white solid. The stoichiometry of this reaction corresponds to 57 parts gold and 70 parts di-amine and presumably leads to a diammonium salt of $\mathrm{AuCl}_{4}$; this is not discussed or verified. The isolated material is then further reacted with a mixture of the alkyl amine and decanoic acid to produce an oil, in the case of decanoic acid/propylenediamine mixtures, which is washed and isolated. A similar reaction uses 2-ethyl-4-methylimidazole as the amine and 2-ethylhexanoic acid, but there is no detail given on the quality of the decorative films produced.

The only other significant use of non-sulphur precursors involves the synthesis of water-soluble gold clusters based on triarylphosphine ligands (26). The aryl groups were functionalised with sulphonic acid groups to impart water solubility.

\section{Gold Nanoparticles}

These are relatively new building blocks for DPM type formulations for producing bright gold films. However, colloidal purple of cassius gold stains have been known for centuries and are still used to produce a range of colours for tableware and porcelain decorations. A recent patent (27) discusses the use of gold-nanoparticles predominantly stabilised with mercaptide ligands that are beneficial in DPM compositions.

Preparation of thiol-stabilised gold nanoparticles has been achieved using the Brust method (28) and involves reduction of thiol/AuCl ${ }_{4}^{-}$mixtures in an organic solvent such as toluene with sodium borohydride. The resulting intensely dark solution can be concentrated and a black solid precipitated from large quantities of alcohol such as methanol. The resulting nanoparticles can be re-dissolved or re-dispersed when desired into DPM type formulations. Aromatic or alkyl mercaptides have been used as stabilising ligands. The aromatic ligands are, preferably, mono-substituted with branched alkyl moieties. Thiol-stabilised gold nanoparticles appear to reduce covercoat interaction in water transfer or decal applications. Such interactions result in purple hazing at the edges of the gold line.

When using the ligand $p$-tert-butylphenyl mercaptide, TGA analysis indicated clean removal of the thiol stabilising ligand at $226^{\circ} \mathrm{C}$. Typical particle size distributions for these materials determined by TEM are reported to be in the range 0.5 to $2 \mathrm{~nm}$. Typical UV spectra displayed a characteristic weak surface plasmon band around $500 \mathrm{~nm}$. On reducing the thiol concentration the plasmon band grows in strength and consequently the gold assay also increases. In addition, solubility in toluene decreased compared to when using 
higher mole equivalents of the stabilising thiol. These results follow the same trends reported by previous workers (29).

\section{Mechanistic Studies}

The thermal properties of gold mercaptides discussed in this review have defined the point at which a molecular gold species forms a conductive film. However this data alone does not give an insight into the thermal decomposition and metallisation pathway for the formation of thin metallic gold films. There is a dearth of publications that discuss thermally induced metallisation reactions for gold-mercaptides. However there are two relevant reports and comment is now made as to how such studies could act as a catalyst to future work.

Controlled thermolysis on a series of anionic gold(I)mercaptide powders has been studied by Nakamoto (30). Compounds used were:-

$\left[\mathrm{R}\left(\mathrm{CH}_{3}\right)_{3} \mathrm{~N}\right]\left[\mathrm{Au}\left(\mathrm{SC}_{12} \mathrm{H}_{25}\right)_{2}\right] \quad\left[\mathrm{R}\left(\mathrm{CH}_{3}\right)_{3} \mathrm{~N}\right]\left[\mathrm{Au}\left(\mathrm{SC}_{6} \mathrm{H}_{4}-\mathrm{p}-\mathrm{R}^{\prime}\right)_{2}\right]$

where $\mathrm{R}=\mathrm{C}_{14} \mathrm{H}_{29}, \mathrm{C}_{12} \mathrm{H}_{25} ; \mathrm{R}^{\prime}=\mathrm{C}_{8} \mathrm{H}_{17}, \mathrm{CH}_{3}$.

In a specific example, the solid-state thermolysis of the $\left[\mathrm{C}_{14} \mathrm{H}_{29}\left(\mathrm{CH}_{3}\right)_{3} \mathrm{~N}\right]\left[\mathrm{Au}\left(\mathrm{SC}_{12} \mathrm{H}_{25}\right)_{2}\right]$ at $180^{\circ} \mathrm{C}$ for $5 \mathrm{~h}$ under an $\mathrm{N}_{2}$ produced a new nanoparticle stabilised with alkyl groups derived from the precursor complex. The average particle size of the nanoparticles was found to be $26 \mathrm{~nm}$.

TEM and X-ray-photoelectron spectroscopy (XPS) were used to determine the particle size distribution and oxidation state of the gold particles. XRD was employed to determine metallic particle size and crystallinity, and a combination of FAB mass spectrometry and GC-MS used to determine the fate of the organic ligands, and the thermal degradation mechanism of these materials. UV-vis spectrometry was also employed to verify the presence of metallic particles by observation of characteristic plasmon absorption bands for gold in the 520-540 $\mathrm{nm}$ region.

Results showed that control of nanoparticle size could be achieved by variation of the heating time and peak temperature, and that the stabilising ligand for the gold nanoparticles was not mercaptide but alkyl groups arising from the quaternary ammonium cation present in the precursor. Reductive elimination of the mercaptide ligand was shown to occur during thermolysis forming disulphide and $\mathrm{Au}(0)$. For the aromatic mercaptides, the length of the $p$ - R' group also appears to influence the particle size distribution of the gold nanoparticles, with the longer octyl chain length restricting particle aggregation compared to the methyl group.

The thermal decomposition data of a series of water soluble polynuclear gold $(I)$-mercaptides including $\left\{\mathrm{Au}\left(\mathrm{SCH}_{2} \mathrm{CO}_{2} \mathrm{H}\right)\right\}_{n}$, $\left\{\mathrm{Au}\left(\mathrm{SCH}_{2} \mathrm{CH}_{2} \mathrm{CO}_{2} \mathrm{H}\right)\right\}_{n}$ and $\left\{\mathrm{Au}\left(\mathrm{SCH}_{2} \mathrm{CH}_{2} \mathrm{CH}_{2} \mathrm{CO}_{2} \mathrm{H}\right)\right\}_{n}$ have been investigated using Simultaneous Thermal Analysis (STA) and
Thermal Gravimetric-Evolved Gas Analysis (TG-EGA) techniques in an atmosphere of flowing air (31). The STA technique determines weight loss data and indicates whether these are endothermic or exothermic. EGA determines, via mass spectrometry, the nature of evolved gases.

Data obtained from these thermal analytical techniques indicated that all three gold-mercaptide complexes decompose via a two-stage weight loss process, with the initial major weight loss (26-35\% wt loss) complete by $250^{\circ} \mathrm{C}$, and this is followed by a small weight loss (3-5\%wt loss) up to $500^{\circ} \mathrm{C}$. Final residues were consistent with the formation of gold metal. The initial process was endothermic, and the small weight loss exothermic.

For $\left\{\mathrm{Au}\left(\mathrm{SCH}_{2} \mathrm{CO}_{2} \mathrm{H}\right)\right\}_{n}$ there is a close correlation between the weight losses observed by simultaneous thermal analysis, and those predicted theoretically for a two stage decomposition process involving a gold(I)-sulphide intermediate species. EGA indicated that quantities of carbon dioxide and carbon disulphide were evolved during the initial weight loss. The secondary weight loss is exothermic, which is consistent with the evolution of the sulphur as sulphur dioxide as determined via EGA studies.

Similarly, for $\quad\left\{\mathrm{Au}\left(\mathrm{SCH}_{2} \mathrm{CH}_{2} \mathrm{CO}_{2} \mathrm{H}\right)\right\}_{n}$ and $\left\{\mathrm{Au}\left(\mathrm{SCH}_{2} \mathrm{CH}_{2} \mathrm{CH}_{2} \mathrm{CO}_{2} \mathrm{H}\right)\right\}_{n}$ the weight loss data observed corresponds to thermal decomposition occurring via a similar two stage process. For $\left\{\mathrm{Au}\left(\mathrm{SCH}_{2} \mathrm{CH}_{2} \mathrm{CO}_{2} \mathrm{H}\right)\right\}_{n}$ propenoic acid is observed in the first weight loss again indicating gold-sulphide intermediate species. Further details are reported in reference (31) together with data for a wider range of water soluble gold-mercaptides.

Although the atmospheric reaction conditions and gold nuclearity are different for the two studies above, in the temperature region of $25-250^{\circ} \mathrm{C}$, differences in thermal decomposition pathways to metallic gold have been demonstrated. The Nakamoto work has shown that reductive elimination of mercaptides occurs for these mononuclear gold compounds with formation of disulphide by-products, whereas work in our laboratories has shown that for polymeric gold-mercaptides decomposition can occur with formation of gold-sulphide intermediate products (based on weight data from STA and EGA studies).

\section{Future Trends}

Nakamoto's work demonstrates a novel method for preparing stabilised nanoparticles via thermolysis of gold mercaptides. Preparative methods for gold nanoparticles stabilised with mercaptide ligands displaying a range of particle sizes is becoming a well established area with a rapid increase in studies over the last five years (32). The reason for the interest is in the application of nano-engineered 
material/arrays for electronic and sensor applications (33). A number of parallels can be used from these studies to aid the understanding of the thermal decomposition mechanism of gold-mercaptides. For example research has shown (34) that highly ordered 2-dimensional arrays of mercaptide stabilised gold nanoparticles can be deposited to produce thin films. TEM and XRD data shows these materials are highly orientated crystalline gold particles. This is not dissimilar to decorative bright films, which have film thickness in the region of 50-150 nm and, based on XRD studies, display high degrees of crystallinity and orientation (35).

The ordered gold nanoparticles produced by room temperature fabrication techniques should be considered as intermediate gold film precursors. The combination of analytical techniques discussed above has demonstrated that good quality mechanistic data can be obtained for these gold metallisation processes. Studies relating the class of gold-mercaptide employed to film growth and metallisation temperature and subsequent bulk film quality such as brightness or structure could have commercial benefits in the following areas for decorative or electronic applications:

1. Control of colloidal growth of intermediate gold species formed prior to gold film formation to influence properties such as film colour, brightness and chemical durability.

2. Effective control of metallisation temperature to allow for additions of fusible refractory glassy materials to cover the decorative films to impart microwave resistivity or very high abrasion resistance. These are desirable commercial properties for gold decorated microwavable mugs, dishes and for scratch-resistant tiles respectively.

3. Increase knowledge of thermal decomposition mechanisms to provide pathways that allow decomposition of gold mercaptides in the region of $25-100^{\circ} \mathrm{C}$. This could be applicable to electronics applications where low temperature conducting tracks on plastic substrates are required.

\section{Concluding Remarks}

The data arising from the series of Fitch patents has demonstrated that, by variation of the mercaptide ligand on the gold precursor, a significant variation in temperature towards gold metallisation can occur. Any defined correlation between gold-mercaptide type and thermal data is not possible. Further work is required to make firm predictions and would be beneficial in predicting metallisation temperatures for DPM type formulations. Directions for further work have been discussed and these involve using a combination of spectroscopic, thermal and electron optic techniques to pinpoint intermediate gold species along the pathway to decorative bright films.
Structural data is limited; but data presented above indicate solid state arrays that are novel and are dominated by $\mathrm{Au}(\mathrm{I})-\mathrm{Au}(\mathrm{I})$ interactions. If good quality crystals can be grown for other gold mercaptide species, then new structural arrays may be revealed.

The last 40 years have seen a trend of moving away from obnoxiously smelling mercaptide ligand systems, soluble in hydrocarbon and chlorinated solvents, to functionalised mercaptides having solubility in water.

New materials, such as mercaptide stabilised gold nanoparticles, have been developed for decorative applications; but, very little work has been carried out on non-sulphur gold compounds for DPMs. The reasons for this are unclear and further work is required.

An advantage of gold mercaptides is the wide diversity in physical and chemical properties available by varying the $R$ group, together with the high solution stability required for commercial DPM type applications. Such properties would be required for non-sulphur precursors.

\section{About the Author}

Dr Peter Bishop is a Scientific Consultant at the Johnson Matthey Technology Centre near Reading in the UK and is responsible for research projects for the Colours and Coatings division of Johnson Matthey. He obtained his PhD from the University of Essex in 1987 in the area of metal-thiolate coordination chemistry. His research and expertise over the last 14 years at Johnson Matthey has involved gold and silver sulphur-based molecular and nanoparticle chemistry, thin film deposition technology and solid state synthetic chemistry of inorganic pigments.

\section{References}

1 R.J. Puddephatt in 'Cold, Progress in Chemistry, Biochemistry and Technology', Ed. H. Schmidbauer, John Wiley \& Sons, 1999, pp. 237-257

2 G. Landgraf in 'Cold, Progress in Chemistry, Biochemistry and Technology', Ed. H. Schmidbauer, John Wiley \& Sons, 1999, pp. 143-173

3 A.N. Papzian, Gold Bulletin, 1982, 15, 3

4 S.L. Cantor, Gold Bulletin, 1983, 16, 41

5 L.B. Hunt, Gold Bulletin, 1979, 12, 116

6 E. Ott, US Patent US 2,034,665, 1936

7 K.H. Ballard, US patent US 2,490,399, 1949

8 H.M. Fitch, US patent US 2,994,614, 1961

9 H.M. Fitch, US patent US 3,163,665, 1964

10 H.M. Fitch, US patent US 2,984,575, 1961

11 H.M. Fitch, US patent US 3,245,809, 1966

12 H. Adams, N.A. Bailey, S.R. Gay, L.J. Gill, T. Hamilton and M.J. Morris, J. Chem. Soc., Dalton Trans., 1996, 12, 2403-2407 
13 W. Wojnowski, B. Becker, J. Sassmannhausen, E.M. Peters, K. Peters and H.G. Von Schnering, Z. Anorg. Allg. Chem., 1994, 620, 1417

14 P.J. Bonasia, D.E. Gindleberger and J. Arnold, Inorg. Chem., 1993, 32, 5126

15 I. Schroter and J. Strahle, Chem. Ber., 1991, 124, 2161

16 A.K.H. Al-Sa'ady, K. Moss, C.A. McAuliffe and R.V. Parish, J. Chem. Soc., Dalton Trans., 1984, 1609

17 M.R. Wiseman, P.A. Marsh, P.T. Bishop, B.J. Brisdon and M.F. Mahon, J. Am. Chem. Soc., 2000, 122, 12598

18 H.M. Fitch and R.C. Langley, US Patent US 3,313,632, 1967

19 V.B. Baltrushaitis and K. Sadauskas, US Patent US 4,221,826, 1980

20 M. Lotze and H. Mehner, US Patent US 5,328,769, 1991

21 P.T. Bishop, European Patent 0514 073, 1994

22 A. Shultz and M. Hofler, German patent DE 4405932, 1995

23 A. Shultz and M. Hofler, US Patent US 5,705,664, 1998

24 A. Schulz and M. Hofler, US Patent US 5,639,901, 1997

25 A. Liang, US Patent US 4,201,719, 1980

26 A. Shultz and N. Giesecke, European patent 0857 707, 1998 PCT/GB01/01081, 2001

28 M. Brust, M. Walker, D. Bethell, D.J. Schiffrin and R. Whyman, J. Chem. Soc., Chem. Commun., 1994, 801

29 S. Chen and R.W. Murray, Langmuir, 1999, 15, 682-689 and references therein

30 M. Nakamoto, M. Yamamoto and M. Fukusumi, J. Chem. Soc., Chem. Commun., 2002, 1622

31 P.A. Marsh, 'Metal Complexes as Precursors for Film Deposition Processes' Thesis, Open University, 1998

32 H. Bonnemann and R.M. Richards, Eur. J. Inorg. Chem., 2001, 24552480

33 'Metal Nanoparticles, Synthesis, Characterisation and Applications', ed. D.L. Feldheim and Colby A. Foss, Jr., Mercel Dekker, 2002, chapters 8 and 13 and references therein.

34 C.J. Keily, J. Fink, M. Brust, D. Bethell and D.J. Schiffrin, Nature, 1998, 396, 444

35 P.T. Bishop and P.A. Marsh, unpublished data

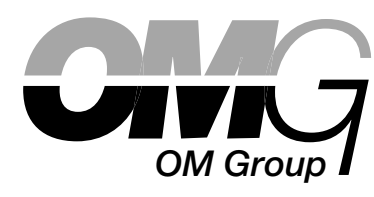

Electronic Chemicals

\section{Degussa Galvanotechnik $\mathrm{GmbH}$ - Change of Corporate Name}

As of April 15, 2002, Degussa Galvanotechnik GmbH in Schwäbisch Gmünd, Germany changed it's name to OMG Galvanotechnik $\mathbf{G m b H}$.

The precious metal activities of Degussa AG have been successfully integrated into OMG, headquartered in Cleveland, Ohio, USA. It is now a new member of OM Group, which has strategic orientation to metal-based speciality chemicals. OMC Galvanotechnik $\mathrm{GmbH}$ in Schwäbisch Gmünd is a leading supplier of electrolytic precious metal electrolytes and salt compounds as well as electrolytes for the deposition of copper alloys.

OMG Galvanotechnik GmbH, Klarenbergstraße 53-79, D-73525 Schwäbisch Gmünd, Germany, is now a part of OMG's Electronic Chemicals group.

For more information on OMG Galvanotechnik, contact:

Tel: $\quad+497171607218$

Fax: +497171607264

E-mail: karin.barth@eu.omgi.com

Website: www.omg-galvano.com 